\title{
Effects of Nigerian Piliostigma thonningii Species Leaf Extract on Lipid Profile in Wistar Rats
}

\author{
O. M. Ighodaro and J. O. Omole \\ Biochemistry Laboratory, Lead City University, Ibadan, Nigeria \\ Correspondence should be addressed to O. M. Ighodaro, macigho@yahoo.com
}

Received 12 July 2012; Accepted 3 August 2012

Academic Editors: G. Edwards, R. Fantozzi, T. Kumai, J. C. Laguna, and T. B. Vree

Copyright ( $) 2012$ O. M. Ighodaro and J. O. Omole. This is an open access article distributed under the Creative Commons Attribution License, which permits unrestricted use, distribution, and reproduction in any medium, provided the original work is properly cited.

\begin{abstract}
Cardiovascular complications and associated conditions remain a major cause of death, globally. Piliostigma thonningii has been used for different and several medicinal purposes. On this background, the effect of aqueous leaf extract of the plant on the lipid profile of physiologically normal rats was examined. Graded doses of the extract, $0.0,0.2$, and $0.4 \mathrm{~g} / \mathrm{kg}$ of body weight (bwt) were orally administered to rats for a period of 14 days. The effect of the extract was assessed on the basis of comparative determinations of the evaluated indices in treated rats vis-à-vis the nontreated group as well as in respect to the differences between the basal and final concentrations of the indices in each group. The extract, especially at $0.2 \mathrm{~g}$ per kg body weight caused a significant decrease in the total cholesterol, triglycerides, and low-density lipoprotein (LDL) cholesterol in the treated rats when compared to the control group and basal concentrations. Though, the level of high-density lipoprotein (HDL) cholesterol increased in the treated rats, the increase was not significant when compared to the basal concentration. The LDL/HDL ratio in all the experimental groups was less than 0.9. The results obtained in this study suggest that $P$. thonningii aqueous leaf extract likely contains antilipidaemic and anticholesterolaemic substance(s), which may be useful in the prophylactic and curative management of lipid peroxidation, high blood pressure, and cardiovascular disorders.
\end{abstract}

\section{Introduction}

Cardiovascular diseases and related disorders are a major cause of mortality both in men and women all over the world [1]. They are commonly characterized by high levels of total cholesterol, triglycerides, and low-density lipoprotein cholesterol in the serum. Increased total cholesterol and more significantly LDL cholesterol in the serum have been implicated in the etiology of cardiovascular diseases and are seen as primary risk factors [2]. Also, high level of lipids in the blood has been associated with hypertension and lipid peroxidation [3].

Orthodox medicine, though, is generally preferred and acceptable, traditional medicine is still very much relied on all over the world $[4,5]$. This is common in the developing countries where the cost of orthodox medicine is astronomical and unaffordable to a large size of the populace [6]. According to World Health Organization, about $80 \%$ of folks in developing countries depend mainly on traditional medicine for their primary health care, and about $85 \%$ of such traditional medicine involves the use of plant extracts [7].

Some commonly consumed herbs have been reported to promote reduction in blood lipids [8-10]. P. thonningii is an under-explored leguminous plant that belongs to the family, Leguminosae-Caesalpiniodae. The tree is perennial in nature, and the petals varies from white to pink in colour and are produced between November and April [11]. Silva and colleagues [12] reported that in many African countries various parts of $P$. thoninngii (organs: root, bark, seed, and fruit) are used for various medicinal purposes. For instance, the plant is used to treat wounds, ulcers, gastric/heart pain, gingivitis, and as an antipyretic. In Tanzania and Zimbabwe, a cough remedy is prepared from the root bark; this fraction exhibits significant anti-inflammatory/analgesic activity. Certain compounds isolated from its leaves have been reported to elicit anti-inflammatory and antibacterial activities [13]. 
Generally, plants reported to exhibit lipid lowering activity are rich in flavonoids and tannins which play significant role in the mobilization and metabolism of lipids. Preliminary phytochemical studies on Piliostigma thonningii reveals high levels of flavonoids, tannins, and alkaloids [14]. The plant is also reported to contain nutritionally important vitamins (such as $\mathrm{C}$, E, and beta-carotene) and minerals (such as calcium, magnesium, zinc, and potassium) all of which contriuibute to its high-antioxidant properties). Against high incidence of cardiovascular diseases, there is paucity of information on scientifically verified plants with antilipidaemic and anticholesterolaemic properties.

In light of the chemical constituents of $P$. thonningii, this study was designed to evaluate the effect of its aqueous leaf extract on the blood lipid profile in rats.

\section{Materials and Methods}

2.1. Preparation and Administration of the Plant Material. Fresh Piliostigma thonningii leaves were harvested as one batch in the month of June 2010 at Abeokuta, Ogun state, Nigeria. The botanical identification was confirmed at the Herbarium of the Department of Botany, University of Ibadan. The leaves were freed of extraneous materials, airdried, and ground into a uniform powdery form using a milling machine. The powdered leaf was macerated and extracted in $2.5 \mathrm{~L}$ distilled water at room temperature for $48 \mathrm{hrs}$, with occasional shaking. The filtrate obtained was concentrated under reduced pressure at $60 \pm 1^{\circ} \mathrm{C}$ in a rotary evaporator. Drying and solvent elimination gave a light brown extract. This crude aqueous extract was used, without further purification.

2.2. Animal Management and Administration. Thirty male albino rats of the Wistar strain were used for the study. They were purchased from the Institute for Advance Medical Research and Training (IMRAT), at the University College Hospital $(\mathrm{UCH})$, Ibadan. The animals were handled humanely, kept in a plastic suspended cage placed in a wellventilated and hygienic rat house under suitable conditions of temperature and humidity. They were provided rat pellets and served water ad libitum and subjected to natural photoperiod of $12 \mathrm{hrs}$ light and $12 \mathrm{hrs}$ dark cycle. The rats attained a body weight range of 200-220 g before they were used for this study. The animals were randomly assigned into three (3) groups, A, B, and C with each group containing ten animals $(n=10)$. Group A (control) were given normal saline daily for 14 days. Group B were treated orally with $0.2 \mathrm{~g} / \mathrm{kg}$ bwt of $P$. thonningii extract daily for 14 days. Group $\mathrm{C}$ were treated orally with $0.4 \mathrm{~g} / \mathrm{kg}$ bwt of the extract daily for 14 days. All animals were given access to normal laboratory chow and water ad libitum during the study.

At the onset of the study, blood samples were collected separately from each rat in all the groups via the retro orbital sinus of the eye by ocular puncture into nongheparinized bottles. After 14 days, the animals (treated and nontreated) were fasted overnight, blood samples were again collected and the animals were then sacrificed by cervical dislocation.
The blood samples collected before and after treatment were left to clot and sera were obtained by centrifugation at $3000 \times \mathrm{g}$ for $10 \mathrm{~min}$. There was no use of anesthesia during the study.

2.3. Estimation of Lipid Profile. The sera obtained above were used for the biochemical analyses of total cholesterol, triglycerides, low-density lipoprotein (LDL) cholesterol, and high-density lipoprotein (HDL) cholesterol. Total cholesterol and triglycerides were determined by the methods of Braun [15] and Stein and Myers [16], respectively. Determination of LDL cholesterol was by the method of Friedewald et al. [17] and the method of Hiller [18] was used to estimate HDL cholesterol. The LDL-HDL ratio for each group was estimated mathematically

2.4. Statistical Analysis. Results are presented as mean \pm S.D (standard deviation of the mean) and $n$ represents the number of rats used for each experiment. Comparisons were done between groups and between the basal and final concentrations in each by use of one-way analysis of variance (ANOVA) followed by post hoc tests (leastsquare deviation). $P$ value of less than 0.05 was declared as significant statistically.

\section{Results and Discussion}

The determined concentrations of total cholesterol, triglycerides, low-density lipoprotein (LDL) cholesterol, and highdensity lipoprotein (HDL) cholesterol in both nontreated and treated rats at $0 \mathrm{hr}$ (basal concentration) and after 14 days are presented in Tables 1, 2, and 3, respectively.

In order to establish a definite and significant effect of $P$. thonningii leaf extract on the serum lipids of rats in this study, it was necessary to observe how the levels of these lipids varied in rats which were not treated with the extract within the period of the study. The results in Table 1 showed that there were no significant differences in the concentrations of total cholesterol, triglycerides, LDL cholesterol and HDL cholesterol at zero hour and after 14 days in rats which were not treated with piliostigma thonningii leaf extract. This implied that there was no significant difference between the initial levels of total cholesterol, triglycerides, LDL cholesterol, and HDL cholesterol, and the final concentrations after 14 days in the nontreated rats (Table 1). This observation is very important as it substantiates any effects of the plant extract on the treated rats.

There was significant $(P<0.05)$ decrease in total cholesterol (by $18.6 \%$ ), triglyceride (by $20.46 \%$ ) and LDL cholesterol (by 20.42\%) in groups treated with $0.2 \mathrm{~g} / \mathrm{kg}$ of piliostigma thonningii leaf extract (Table 2). $0.4 \mathrm{~g} / \mathrm{kg}$ of the extract did not elicit a higher effect on the lipid profile of rats. On the contrary, a relative lower reduction in total cholesterol (by 15.18\%) triglyceride (by 19.04\%), and LDL cholesterol (by 15.96\%) was observed in rats treated with $0.4 \mathrm{~g} / \mathrm{kg}$ of the extract (Table 3 ). Both doses of the extract elicited a nonsignificant increase in high-density lipoprotein cholesterol in rats. This observation is based 
TABLE 1: Levels of serum lipids at zero hour and after 14 days in control ( $0.0 \mathrm{~g} / \mathrm{kg}$ bwt of extract).

\begin{tabular}{lcccc}
\hline Period & Total cholesterol $(\mathrm{mg} / \mathrm{dL})$ & Triglycerides $(\mathrm{mg} / \mathrm{dL})$ & LDL cholesterol $(\mathrm{mg} / \mathrm{dL})$ & HDL cholesterol $(\mathrm{mg} / \mathrm{dL})$ \\
\hline $0 \mathrm{hr}$ & $113.34 \pm 2.3$ & $104.56 \pm 4.5$ & $45.89 \pm 3.9$ & $43.74 \pm 2.8$ \\
14 days & $112.76 \pm 1.3$ & $106.91 \pm 3.1$ & $44.76 \pm 2.4$ & $43.98 \pm 1.8$ \\
\hline
\end{tabular}

Presented values are mean \pm S.D of ten rats. LDL: low-density lipoprotein, HDL: high-density lipoprotein.

TABLE 2: Levels of serum lipids at zero hour and after 14 days in rats treated with $0.2 \mathrm{~g} / \mathrm{kg}$ bwt of extract.

\begin{tabular}{lcccc}
\hline Period & Total cholesterol $(\mathrm{mg} / \mathrm{dL})$ & Triglycerides $(\mathrm{mg} / \mathrm{dL})$ & LDL cholesterol $(\mathrm{mg} / \mathrm{dL})$ & HDL cholesterol $(\mathrm{mg} / \mathrm{dL})$ \\
\hline $0 \mathrm{hr}$ & $112.85 \pm 1.5$ & $104.24 \pm 4.5$ & $46.19 \pm 2.0$ & $44.14 \pm 4.8$ \\
14 days & $91.76 \pm 3.6^{*}$ & $82.91 \pm 3.1^{*}$ & $36.76 \pm 2.4^{*}$ & $48.98 \pm 1.8$ \\
\hline
\end{tabular}

Presented values are mean \pm S.D of ten rats. $P<0.05=$ significance; * : compared to basal concentration/control.

TABLE 3: Levels of serum lipids at zero hour and after 14 days in rats treated with $0.4 \mathrm{~g} / \mathrm{kg}$ bwt of extract.

\begin{tabular}{lcccc}
\hline Period & Total cholesterol $(\mathrm{mg} / \mathrm{dL})$ & Triglycerides $(\mathrm{mg} / \mathrm{dL})$ & LDL cholesterol $(\mathrm{mg} / \mathrm{dL})$ & HDL cholesterol $(\mathrm{mg} / \mathrm{dL})$ \\
\hline $0 \mathrm{hr}$ & $114.25 \pm 2.1$ & $105.13 \pm 2.5$ & $46.12 \pm 2.9$ & $43.84 \pm 1.2$ \\
14 days & $96.91 \pm 3.6^{*}$ & $85.11 \pm 3.1^{*}$ & $38.76 \pm 2.4^{*}$ & $49.38 \pm 0.5$ \\
\hline
\end{tabular}

Presented values are Mean \pm S.D of ten rats. $P<0.05$ = Significance; ${ }^{*}$ compared to basal concentration/control.

on the comparative measures of the basal $(0 \mathrm{hr})$ and final concentrations (after 14 days) of the assessed indices in the treated groups.

Lipids are generally characterized by insolubility in aqueous or polar solvents but highly soluble nonpolar or organic solvents. Biochemical reactions and transportations of molecules generally occur in aqueous medium. Hence, lipids are normally combined with specific proteins to form structures called lipoproteins which possess substantial degree of hydrophilicity. Low density lipoproteins, highdensity lipoproteins, and chylomicrons which are basically composed of triglycerides are integral parts of the serum lipoproteins [19]. Except for the HDL cholesterol, high level of all lipids in the blood is arguably a high risk factor in the onset of cardiovascular disorders. High serum concentrations of triglycerides and LDLs have been reported to cause atherosclerosis and coronary heart diseases [20].

Cholesterol is the principal sterol in animal tissues and occurs mainly in the cell membrane due to its amphipatic nature [21]. It is also found in the adrenal gland, liver, brain, and nervous system [22]. The molecule is synthesized basically from acetyl CoA in the liver from where it is distributed through the blood to extrahepatic tissues where it is utilized for the synthesis of bile acids and steroid hormones as well as regulation of membrane fluidity. However, high level of cholesterol in the blood has adverse effects on human health. It is reportedly a major cause of cardiovascular derangements such as atherosclerosis, myocardial infarction and coronary heart diseases.

In this study, piliostigma thonningii leaf extract at the administered doses ( 0.2 and $0.4 \mathrm{~g} / \mathrm{kg}$ bwt) has been observed to cause significant reduction in the serum levels of total cholesterol, triglycerides, and LDL cholesterol in rats. The extract also simultaneously produced elevated level of HDL cholesterol. There is a possibility that the the extract possess the ability to facilitate the transport of cholesterol and triglycerides from the blood into tissues. This may have probably occurred through the induction or suppression of certain enzymes critical to the metabolism of these lipids. This observation is similar to the report of Adebayo et al., 2006 in which Commiphora africanana extract showed antilipidaemic and anticholesterolaemic activities in rats.

Also, the phytochemicals present in medicinal plants are basically responsible for the definite pharmacological effects they exert on the human body.

Flavonoids, alkaloids, cardiac glycosides, and tannins have been reported to play very important roles in lipidmetabolism and protective functions against the incidence of lipid peroxidation and cardiovascular diseases [23].

Piliostigma thonningii is rich in flavonoids, tannins and alkaloids [14], and antioxidant molecules (such as C, E, and beta-carotene). These molecules are likely responsible for the hypolipidaemic activities elicited by the plant in this study.

Morever, the LDL/HDL ratio is often used as an index for cardiovascular disorders [24], and in this study the LDL/HDL ratio in all the treated groups was less than 0.9 compared to a figure of 1.0 recorded in the control group. These values further strengthen the hypolipidaemic properties of $P$. thonningii extract.

\section{Conclusion}

The overall data obtained in this study suggest that piliostigma thonningii leaves may protect against accumulation of cholesterol and triglycerides in the blood. This may be useful in the treatment or management of atherosclerosis and coronary heart disorders. However, it is strongly recommended that the use of the plant extract should be within the 
limits that are nontoxic to body cells and tissues, preferably between $200-250 \mathrm{mg} / \mathrm{kg}$ of body weight.

\section{References}

[1] S. C. Smith, Heart Diseases Prevention Must Get More Attention, World Health Federation, Circulation, 2004.

[2] J. K. Edijala, S. O. Asagba, G. E. Eriyamremu, and U. Atomatofa, "Comparative effects of garden egg fruit, oat and apple on serum lipid profile in rats fed high cholesterol diet," Pakistan Journal of Nutrition, vol. 4, pp. 245-249, 2005.

[3] R. O. Recknagel, "A new direction in the study of carbon tetrachloride hepatotoxicity," Life Sciences, vol. 33, no. 5, pp. 401-408, 1983.

[4] K. O'brien, "Complementary and alternative medicine: the move into mainstream health care," Clinical and Experimental Optometry, vol. 87, no. 2, pp. 110-120, 2004.

[5] B. Leckridge, "The future of complementary and alternative medicine-models of integration," Journal of Alternative and Complementary Medicine, vol. 10, no. 2, pp. 413-416, 2004.

[6] K. Busia, "Medical provision in Africa-past and present," Phytotherapy Research, vol. 19, no. 11, pp. 919-923, 2005.

[7] W. R. Farnsworth, Biodiversity, National Academy Press, Washington, DC, USA, 1988.

[8] C. Perez, J. R. Canal, J. E. Campillo, A. Romero, and M. D. Torres, "Hypotriglyceridaemic activity of Fiscus caarica leaves in experimental Hypertriglyceridaemic rats," Phytotherapy Research, vol. 13, pp. 188-191, 1999.

[9] A. Cignarella, M. Nastasi, E. Cavalli, and L. Puglisi, "Novel lipid-lowering properties of Vaccinium myrtillus L. leaves, a traditional antidiabetic treatment, in several models of rat dyslipidaemia: a comparison with ciprofibrate," Thrombosis Research, vol. 84, no. 5, pp. 311-322, 1996.

[10] A. H. Adebayo, R. Aliyu, D. Gatsing, and I. H. Garba, "The effects of ethanolic leaf extract of Commiphora Africana (Buseraceae) on lipid profile in rats," International Journal of Pharmacology, vol. 2, no. 6, pp. 618-622, 2006.

[11] F. O. Jimoh and A. T. Oladiji, "Preliminary studies on Piliostigma thonningii seeds: proximate analysis, mineral composition and phytochemical screening," African Journal of Biotechnology, vol. 4, no. 12, pp. 1439-1442, 2005.

[12] O. Silva, S. Barbosa, A. Diniz, M. L. Valdeira, and E. Gomes, "Plant extracts antiviral activity against Herpes simplex virus type 1 and African swine fever virus," International Journal of Pharmacognosy, vol. 35, no. 1, pp. 12-16, 1997.

[13] D. A. Akinpelu and E. M. Obuotor, "Antibacterial activity of Piliostigma thonningii stem bark," Fitoterapia, vol. 71, no. 4, pp. 442-443, 2000.

[14] A. A. Akindahunsi and S. O. Salawu, "Phytochemical screening and nutrient-antinutrient composition of selected tropical green leafy vegetables," African Journal of Biotechnology, vol. 4, no. 6, pp. 497-501, 2005.

[15] H. P. Braun, "National cholesterol education programme. Recommendations for cholesterol measurements," Chemistry, vol. 30, pp. 991-199, 1984.

[16] E. A. Stein and G. L. Myers, "National cholesterol education program recommendations for triglyceride measurement: executive summary," Clinical Chemistry, vol. 41, no. 10, pp. 1421-1426, 1995.

[17] W. T. Friedewald, R. I. Levy, and D. S. Fredrickson, "Estimation of the concentration of low-density lipoprotein cholesterol in plasma, without use of the preparative ultracentrifuge," Clinical Chemistry, vol. 18, no. 6, pp. 499-502, 1972.
[18] A. Hiller, "National cholesterol education programme. Recommendations for HDL-cholesterol measurements," Clinical Chemistry, vol. 33, article 895, 1987.

[19] H. P. Rang, M. M. Dale, J. M. Ritter, and P. Gardner, Pharmacology, Churchill-Livinstone, NewYork, NY, USA, 1995.

[20] L. A. Eisenhaver, L. W. Nicholes, R. T. Spencer, and F. W. Bergan, Clinical Pharmacology and Nursing Managenent, Lippincott, Philadelphia, Pa, USA, 1998.

[21] A. L. Lehninger, D. L. Nelson, and M. M. Cox, Lehninger Principles of Biochemistry, Worth Publishers, New York, NY, USA, 3rd edition, 2000.

[22] C. E. Osmund, Basic Biochemistry of Food Nutrients, Immaculate Publication, Enugu, Nigeria, 1st edition, 2001.

[23] S. Tandon, "Phytochemicals and cardiovascular health," Current R\&D Highlights, vol. 28, pp. 18-22, 2005.

[24] D. B. Panagiotakos, C. Pitsavos, J. Skoumas et al., "Importance of LDL/HDL cholesterol ratio as a predictor for coronary heart disease events in patients with heterozygous familial hypercholesterolaemia: a 15-year follow-up (1987-2002)," Current Medical Research and Opinion, vol. 19, no. 2, pp. 8994, 2003. 

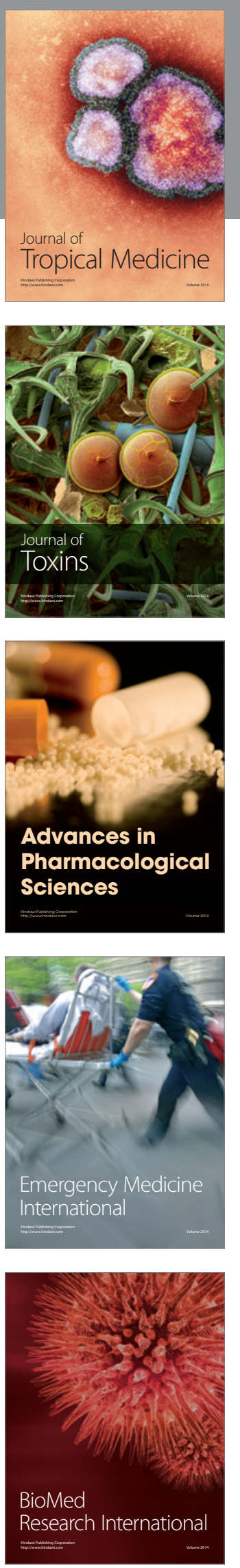
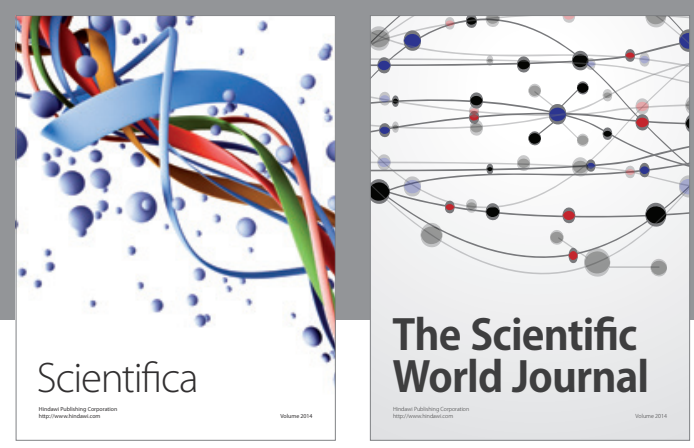

The Scientific World Journal
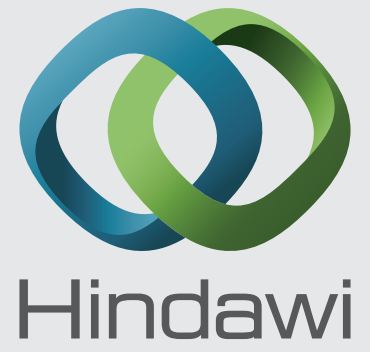

Submit your manuscripts at

http://www.hindawi.com
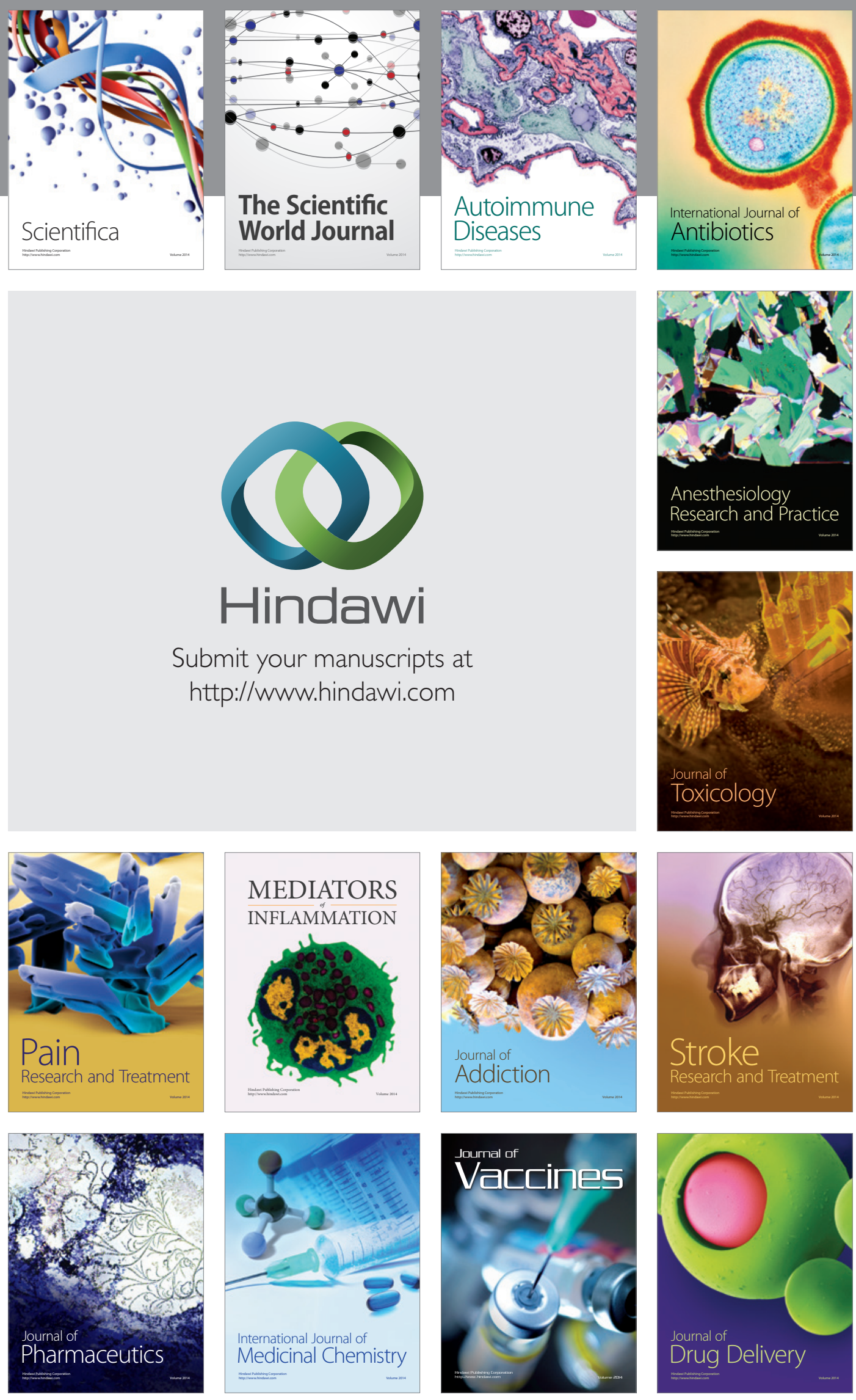